\title{
Rising temperatures reduce global wheat production
}

\section{S. Asseng et al. ${ }^{\dagger}$}

Crop models are essential tools for assessing the threat of climate change to local and global food production'. Present models used to predict wheat grain yield are highly uncertain when simulating how crops respond to temperature ${ }^{2}$. Here we systematically tested $\mathbf{3 0}$ different wheat crop models of the Agricultural Model Intercomparison and Improvement Project against field experiments in which growing season mean temperatures ranged from $15^{\circ} \mathrm{C}$ to $32^{\circ} \mathrm{C}$, including experiments with artificial heating. Many models simulated yields well, but were less accurate at higher temperatures. The model ensemble median was consistently more accurate in simulating the crop temperature response than any single model, regardless of the input information used. Extrapolating the model ensemble temperature response indicates that warming is already slowing yield gains at a majority of wheat-growing locations. Global wheat production is estimated to fall by $6 \%$ for each ${ }^{\circ} \mathrm{C}$ of further temperature increase and become more variable over space and time.

Understanding how different climate factors interact and impact food production ${ }^{3}$ is essential when reaching decisions on how to adapt to the effects of climate change. To implement such strategies the contribution of various climate variables on crop yields need to be separated and quantified. For instance, a change in temperature will require a different adaptation strategy than a change in rainfall ${ }^{4}$. Temperature changes alone are reported to have potentially large negative impacts on crop production ${ }^{5}$, and hotspots-locations where plants suffer from high temperature stress-have been identified across the globe ${ }^{6,7}$. Crop simulation models are useful tools in climate impact studies as they deal with multiple climate factors and how they interact with various crop growth and yield formation processes that are sensitive to climate. These models have been applied in many studies, including the assessment of temperature impacts on crop production ${ }^{1,8}$. However, none of the crop models have been tested systematically against experiments at different temperatures in field conditions. Although many glasshouse and controlled-environment temperature experiments have been described, they are often not suitable for model testing as the heating of root systems in pots ${ }^{9}$ and effects on micro-climate differ greatly from field conditions ${ }^{10}$. Detailed information on field experiments with a wide range of sowing dates and infrared heating recently became available for wheat ${ }^{11,12}$. Such experiments are well suited for testing the ability of crop models to quantify temperature responses under field conditions. Testing the temperature responses of crop models is particularly important for assessing the impact of climate change on wheat production, because the largest uncertainty in simulated impacts on yield arises from increasing temperatures ${ }^{2}$.

In a 'Hot Serial Cereal' (HSC) well-irrigated and fertilized experiment with a single cultivar, the observed days after sowing (DAS) to maturity declined from 156 to 61 days when growing season mean temperatures $\left(T_{\text {mean }}\right)$ increased from $15^{\circ} \mathrm{C}$ to $26^{\circ} \mathrm{C}$ (Fig. 1a,b). The performances of individual models are illustrated in Supplementary Fig. 3. Note that simulations were carried out in a 'blind' test (modellers had access to phenology and yield data of one of the treatments only (normal temperature); see Supplementary Methods). Higher temperatures thus decreased the number of days during which plants could intercept light for photosynthesis, with consequent reductions in biomass (Supplementary Fig. 5) and grain yields (Fig. 1). When $T_{\text {mean }}$ was $>28^{\circ} \mathrm{C}$ and when there were extremely high temperatures early in the growing season with many days of maximum temperature $\left(T_{\max }\right)>34^{\circ} \mathrm{C}$, a critical maximum temperature for wheat ${ }^{13}$, crops did not reach anthesis or grain set, so it was not possible to record anthesis or maturity dates and the yields were zero (Fig. 1a-c and Supplementary Fig. 6a-c). Observed grain yields declined from about $8 \mathrm{tha}^{-1}$ when $T_{\text {mean }}$ was $15^{\circ} \mathrm{C}$ to zero when $T_{\text {mean }}$ was $>28^{\circ} \mathrm{C}$ (Fig. 1c).

Many wheat models simulated the observed anthesis and maturity dates and grain yields when $T_{\text {mean }}$ was between $15^{\circ} \mathrm{C}$ and $20^{\circ} \mathrm{C}$. However, when $T_{\text {mean }}$ reached about $22^{\circ} \mathrm{C}$, observed grain yield measurements were more variable - that is, they had larger standard deviations (s.d.), and models started to deviate from observations (Fig. 1a-c). In some cases, observed grain yields differed by up to $0.7 \mathrm{tha}^{-1}$ (17\% of average yield) with the same $T_{\text {mean }}$. For example, at $T_{\text {mean }}$ of $22.3^{\circ} \mathrm{C}$, some growing seasons had early warmer temperatures that advanced anthesis dates, but cooler temperatures during grain filling that delayed maturity dates, resulting in higher yields. Other seasons had early cooler temperatures during the season that delayed anthesis dates, but warmer temperatures during grain filling that advanced maturity dates, resulting in lower yields. These warmer-to-cooler and coolerto-warmer thermal variations created disparity even though the overall $T_{\text {mean }}$ was the same (Supplementary Fig. 7). As these opposing thermal regimes affect development, gas exchange and water relations of wheat ${ }^{12}$, it is important to consider in-season dynamics when determining grain yield. Many models simulated the dynamic effects on growth (Supplementary Fig. 5a) and yield well (Fig. 1). However, unexplained differences between simulations and some observed yields also exist at around $15^{\circ} \mathrm{C}$, where some of the experimental errors are also large (Fig. 1c). At a seasonal mean temperature of $29^{\circ} \mathrm{C}$ the observed yield was zero and a few models that included heat stress routines affecting canopy senescence, but not necessarily, were able to simulate close-to-zero above-ground biomass and a zero or close-to-zero yield (Supplementary Figs $3 \mathrm{c}$ and 5). At a seasonal mean temperature of $32^{\circ} \mathrm{C}$, about a quarter of all models and the multi-model ensemble median represented the observed zero yields well (Fig. 1c and Supplementary Fig. 3c), as a result of simulated premature crop death, which was consistent with the observations (Supplementary Fig. 5).

A second experimental data set was analysed, focusing on two different cultivars grown at well-irrigated and fertilized International Maize and Wheat Improvement Center (CIMMYT) global sites. The number of days to anthesis and to maturity declined with increasing temperatures, accompanied by yield loss. Model 


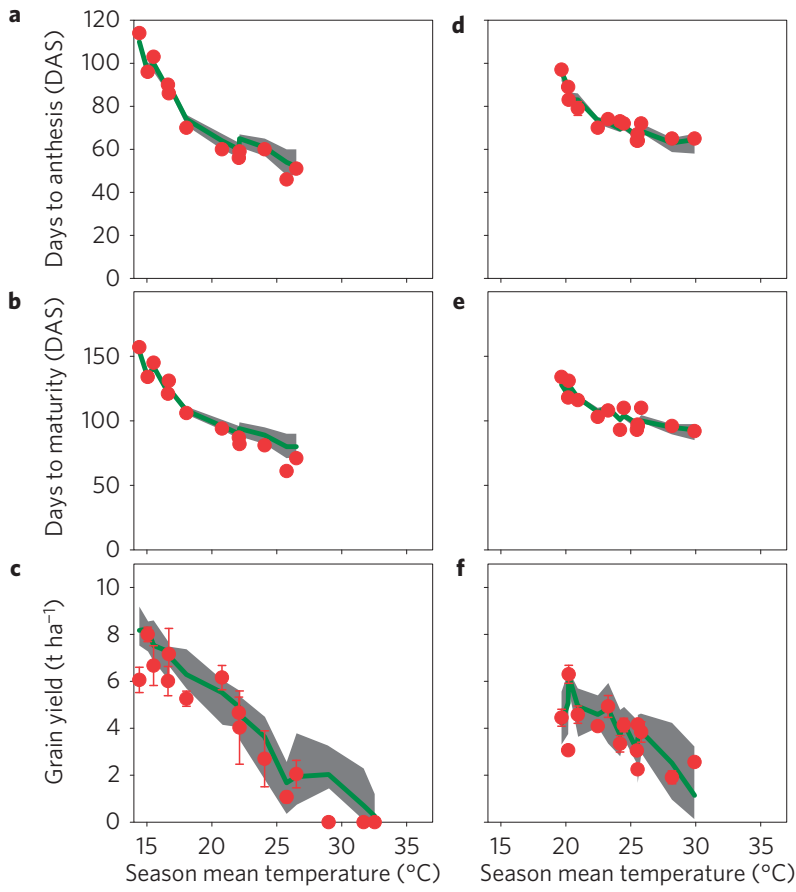

Figure 1 | Observations and multi-model simulations of wheat phenology and grain yields at different mean seasonal temperatures. a-f, Observed values \pm 1 standard deviation (s.d.) are shown by red symbols. Multi-model ensemble medians (green lines) and intervals between the 25th and 75th percentiles (shaded grey) based on 30 simulation models are shown. a-c, 'Hot Serial Cereal' experiment on Triticum aestivum L. cultivar Yecora Rojo with time-of-sowing and infrared heat treatments. DAS,

days-after-sowing. $\mathbf{d}-\mathbf{f}$, CIMMYT multi-environment temperature experiments on T. aestivum L. cultivar Bacanora with time-of-sowing treatments. Note, no anthesis and maturity date measurements were available $>28^{\circ} \mathrm{C}$ in $\mathbf{a}$ and $\mathbf{b}$ owing to premature death of crops. For details of field experiments and calibration steps, see Supplementary Methods. Error bars are not shown when smaller than the symbol.

simulations showed the same temperature responses (Fig. $1 \mathrm{~d}-\mathrm{f}$ and Supplementary Fig. 9). However, unlike the HSC experiment, crops did not fail with $T_{\text {mean }}>28{ }^{\circ} \mathrm{C}$ and still yielded about $2 \mathrm{tha}^{-1}$ of grain. This was despite similar $T_{\max }$ in both experiments during the time after sowing and before the HSC crop died (that is, about 28 DAS; Supplementary Fig. 8). The cultivars Bacanora (Fig. 1d-f) and Nesser (Supplementary Fig. 9) used in the CIMMYT experiments in various locations might be more heat tolerant than the cultivar Yecora Rojo ${ }^{11}$ used in the HSC experiment (Fig. 1a-c). It is known that cultivars have different heat tolerance mechanisms associated with canopy temperature depression via stomata opening and transpirational cooling ${ }^{14}$.

The differences between simulated and observed yields revealed considerable uncertainty, as reported in a previous systematic sensitivity analysis with a large crop model ensemble ${ }^{2}$. Uncertainty increased, particularly at higher temperatures, with models deviating from the observed data at $T_{\text {mean }}>22^{\circ} \mathrm{C}$. However, many of the models simulated the yield decline due to increasing temperatures within the measurement errors ( \pm 1 s.d.). Notably the median of the ensemble of 30 models consistently had the best or near-best skill in reproducing the observed temperature impacts on grain yield, as shown for other crop model ensembles that simulated present growing conditions ${ }^{2,15}$. When considering the subset of treatments in the HSC experiment that were heated artificially in the field with infrared heaters, the simulated relative impact of increased temperature was mostly within the observed relative impact range, and was largest when reference or background temperatures were the highest (Supplementary Fig. 4). In general, the uncertainty in both observed and simulated impacts was relatively large for the artificially heated crops (Supplementary Fig. 4).

Information on cultivars and crop management needed for regional or global modelling studies is sparse ${ }^{16}$. Lack of such information can affect the outcomes of an impact assessment owing to large model input uncertainties ${ }^{2}$. Here, further information on cultivar parameters and phenology improved grain yield simulations for a few individual models (Supplementary Table 4), consistent with previous findings, but had little or even a negative impact on the performance of many other models-and, therefore, on the multimodel ensemble median (Supplementary Fig. 10). Therefore, when using a single model to assess climate change impact, the simulated impacts varied widely depending on the individual model and available information, but the level of information hardly affected the accuracy of the ensemble median impact simulations.

The simulated phenology in crop models can have a large impact on the simulations of other crop processes. When simulating grain yields with a 'fixed phenology', modellers were asked to fix their simulated anthesis and maturity dates as close as possible to the observed dates (that is, root mean square relative error (RMSRE) for anthesis and maturity dates were close to zero (Supplementary Table 4)) to override any inbuilt errors from phenology simulations. Fixing phenology when simulating grain yields had a surprisingly minor effect, and subsequent ensemble yields hardly changed (Supplementary Fig. 10). Furthermore, small errors in simulated phenology did not necessarily translate into errors in yield, particularly if there was compensation between the modelling of pre- and postanthesis processes. This trade-off between pre-anthesis growth and post-anthesis stress exposure is well-documented in late-in-season drought environments ${ }^{17}$ and can be managed by altering sowing dates, cultivar choice and fertilizer inputs. In well-fertilized, irrigated systems without initial water stress, a later-flowering crop will accumulate more biomass and a potentially higher yield, but if it is then exposed to more heat late in the season, grain filling and final grain yield will be reduced. Many models simulated this interaction correctly, compensating for other errors which may disguise erroneous model structures or parameters.

We have shown with the large range of observed data that the simulated wheat crop model ensemble median consistently has better skill in reproducing the observed temperature response than single models and that the level of information on cultivars had little effect on the ensemble median accuracy. Therefore, this 30-model ensemble provides the most accurate estimate of wheat yield response to increased temperature (Fig. 2). Although improvements in technology and management have led to increasing wheat yields around the world, wheat model simulations over the main global wheat-producing regions can isolate the climate signal by holding inputs and management constant with the exception of climate information. Simulated yields declined between 1981 and 2010 (Fig. 2a) at 20 of the 30 representative global locations (Supplementary Figs 11-13) owing to positive temperature trends over the same period (Supplementary Fig. 1). The simulated median temperature impact on yield decline varied widely across 30 global locations and the 30 -year average yields decreased by between $1 \%$ and $28 \%$ across sites with an increase of $2{ }^{\circ} \mathrm{C}$ in temperature and between $6 \%$ and $55 \%$ across sites with an increase of $4{ }^{\circ} \mathrm{C}$ (Fig. 2b,c).

For locations at low latitudes the increase in simulated yield variability with higher temperature was more marked than at high latitudes, because the relative yield decline was greater owing to the higher reference temperatures ${ }^{1}$ (Fig. 2c). However, yield variability expressed in absolute terms hardly changed (Supplementary Fig. 14). Similarly, the year-to-year variability increased at some locations with temperature increases because of greater relative yield reductions in warmer years and lesser reductions in cooler years (Fig. 3a). The increase in year-to-year yield variability is 

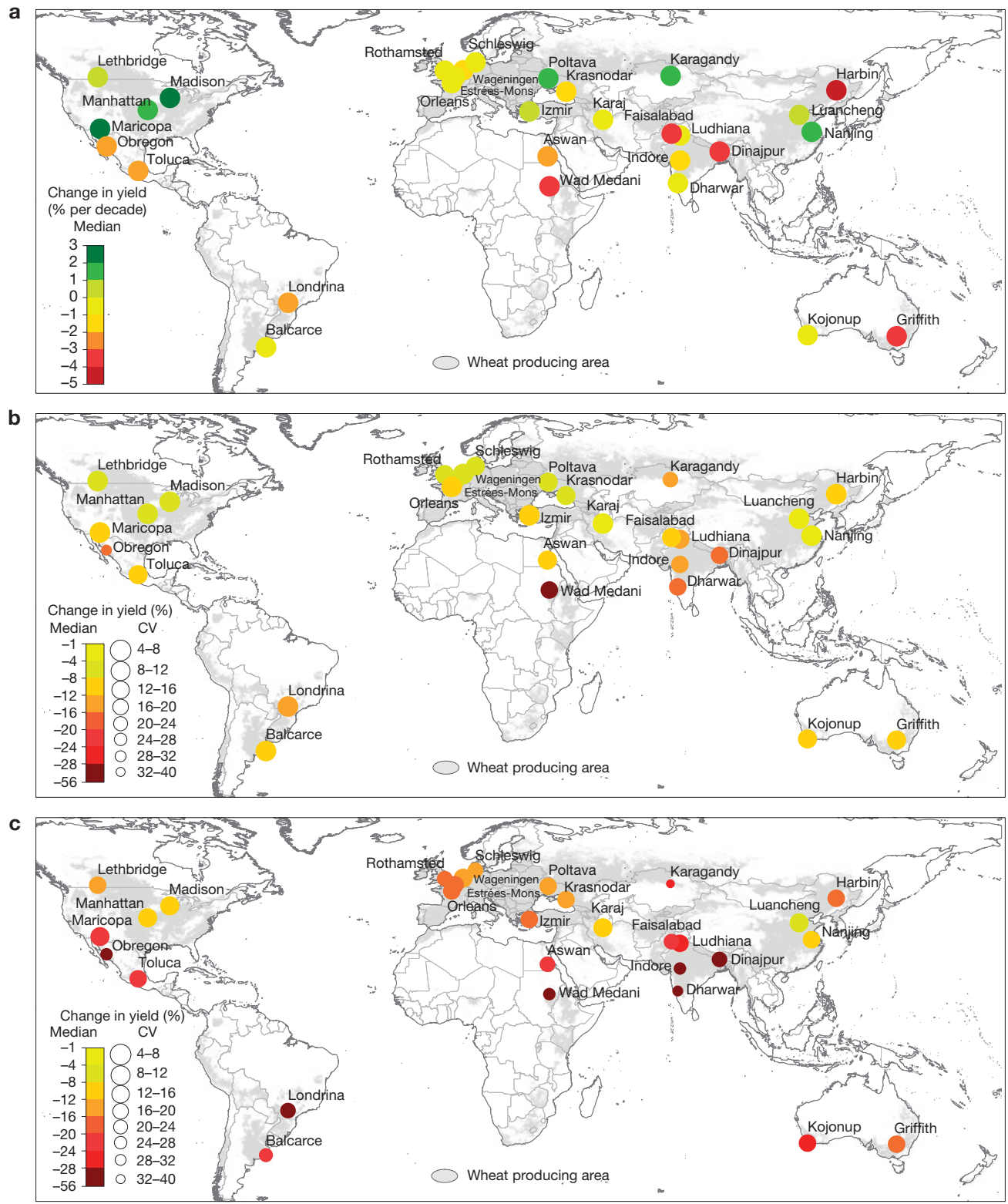

Figure $\mathbf{2}$ | Simulated global wheat grain yield change in the past and with higher temperatures. a, Grain yield trends for 1981-2010 based on the median yield of a 30-model ensemble. b,c, Relative median grain yield for $+2{ }^{\circ} \mathrm{C}(\mathbf{b})$ and $+4{ }^{\circ} \mathrm{C}(\mathbf{c})$ temperature increases imposed on the $1981-2010$ period for the 30 -model ensemble using region-specific cultivars. Simulation model uncertainty was calculated as the coefficient of variation (CV\%) across 30 models and plotted as circle size. The larger the circle, the less the uncertainty.

critical economically as it could decrease some regional—and hence global-stability in wheat grain supply ${ }^{18}$, amplifying market and price fluctuations ${ }^{19}$.

About $70 \%$ of present global wheat production comes from irrigated or high rainfall regions ${ }^{20}$. The global temperature impact simulations were carried out for region-specific cultivars, including spring and winter wheat cultivars (Supplementary Table 3), at key locations in irrigated or high-rainfall regions. All locations had a model ensemble median yield loss on average over 30 years with increasing temperatures (Fig. 2), mainly as a result of a reduced growing period with fewer grains per unit land area (Fig. 3b), also supported by field experiments ${ }^{11}$. Mediterranean-type and arid environments have been studied with single models. Under rain-fed and water- and nitrogen-limited conditions, it was found that seasonal temperature increases of up to $2{ }^{\circ} \mathrm{C}$ increased yields by avoiding water and heat stress at the end of the season ${ }^{21}$. However, other experimental evidence suggests that increased temperature has negative impacts regardless of water ${ }^{22}$ (Supplementary Figs 15 and 16) and $\mathrm{N}$ supply ${ }^{23}$ (Supplementary Fig. 17). Therefore, the simulated temperature impacts are possibly applicable to most cropping systems beyond those that are irrigated or that receive high rainfall. To attempt a global temperature impact estimate, we extrapolated the simulated temperature impacts of the 30 chosen experimental locations to all regional wheat production using country statistics (http://www.fao.org) and disaggregated global mean surface temperature increases to regional surface temperature changes $^{24}$ (see Supplementary Methods and Table 3). For each ${ }^{\circ} \mathrm{C}$ increase in global mean temperature, there is a reduction in global wheat grain production of about $6 \%$, with a $50 \%$ probability of between $-4.2 \%$ and $-8.2 \%$ loss, based on the multi-model ensemble. Considering present global production of $701 \mathrm{Mt}$ of wheat in 2012 (http://www.fao.org) and impacts of temperature only, and assuming no change in production areas or management ${ }^{25}, 6 \%$ means a possible reduction of $42 \mathrm{Mt}$ per ${ }^{\circ} \mathrm{C}$ of temperature increase. To put 
a

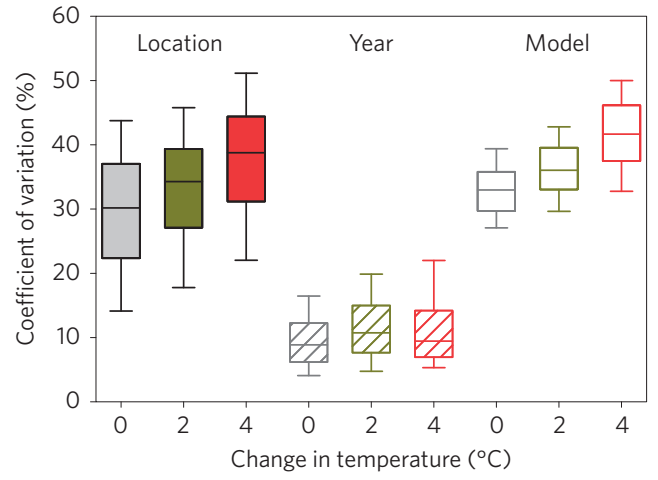

b



Figure $\mathbf{3}$ | Variability, uncertainty and causes of simulated wheat grain yield decline with increasing temperature. a, Coefficient of variation (\%) for simulated grain yields according to location and year variability and model uncertainty. In each box plot, horizontal lines represent, from top to bottom, the 10th percentile, 25th percentile, median, 75th percentile and 90th percentile of 900 simulations for present climate (grey), $+2{ }^{\circ} \mathrm{C}$ (green) and $+4{ }^{\circ} \mathrm{C}$ (red). b, Box plots of simulated multi-model ensemble medians (of 30 models) of 30-year averages for each location of relative change in grain yield, grain number, grain size and harvest index per ${ }^{\circ} \mathrm{C}$ increase. Red lines indicate the simulated mean for 30 locations (not weighted for cropping area). Zero is indicated as a dotted line.

this in perspective, the amount is equal to a quarter of global wheat trade, which reached $147 \mathrm{Mt}$ in 2013 (http://apps.fas.usda.gov). Contrary to some single-model assessments on temperature impacts $^{21,26}$ and a recent multi-model global gridded impact assessment which considered several climate factors together ${ }^{8}$, in response to global temperature increases grain yield declines are predicted for most regions in the world. By extensively ground-truthing models with field measurements and significantly reducing model uncertainty by using model ensemble medians, we demonstrate that wheat yield declines in response to temperature impacts only are likely to be larger than previously thought ${ }^{1}$ and should be expected earlier, starting even with small increases in temperature (Fig. 2).

This study, based on a multi-model ensemble and linked to field data, provides a comprehensive global temperature impact assessment for wheat production. There are several adaptation options to counter the adverse effects of climate change on global wheat production-and for some regions this will be critical. Ensemble crop modelling could be an important exploratory tool in breeding for identified genetic targets ${ }^{27}$ to extend grain filling, delay maturity and improve heat tolerance in wheat cultivars and other cereals.

\section{Methods}

We systematically tested multiple models against field and artificial heating experiments, focusing only on temperature responses. Thirty wheat crop simulation models, 29 deterministic process-based simulation models and one statistical model (Supplementary Tables 1 and 2), were compared with two previously unpublished data sets from quality-assessed field experiments from sentinel sites (see Supplementary Methods) within the Agricultural Model Intercomparison and Improvement Project ${ }^{28}$ (AgMIP; http://www.agmip.org). The first data set was from a 'Hot Serial Cereal' (HSC) experiment with the wheat cultivar Yecora Rojo sown on different dates with artificial heating treatments under well-irrigated and fertilized field conditions ${ }^{11}$. The second data set was from International Maize and Wheat Improvement Center (CIMMYT) experiments testing several cultivars in seven temperature regimes with full irrigation and optimal fertilization and with different sowing date treatments ${ }^{29}$ Using the 30 models, the temperature responses were then extrapolated in a simulation experiment with 30 years of historical climate data from 30 main wheat-producing locations (see Supplementary Methods). Model simulations were executed by individual modelling groups.

Received 4 July 2014; accepted 18 November 2014; published online 22 December 2014

\section{References}

1. Challinor, A. J. et al. A meta-analysis of crop yield under climate change and adaptation. Nature Clim. Change 4, 287-291 (2014).

2. Asseng, S. et al. Uncertainty in simulating wheat yields under climate change. Nature Clim. Change 3, 827-832 (2013).

3. Godfray, H. C. J. et al. Food security: The challenge of feeding 9 billion people. Science 327, 812-818 (2010).

4. Reynolds, M. P., Hays, D. \& Chapman, S. in Climate Change and Crop Production (ed. Reynolds, M. P.) 71-91 (CABI Climate Change Series, 2010).

5. Asseng, S., Foster, I. \& Turner, N. C. The impact of temperature variability on wheat yields. Glob. Change Biol. 17, 997-1012 (2011).

6. Gourdji, S. M., Sibley, A. M. \& Lobell, D. B. Global crop exposure to critical high temperatures in the reproductive period: Historical trends and future projections. Environ. Res. Lett. 8, 1-10 (2013).

7. Teixeira, E. I., Fischer, G., van Velthuizen, H., Walter, C. \& Ewert, F. Global hot-spots of heat stress on agricultural crops due to climate change. Agric. Forest Meteorol. 170, 206-215 (2013).

8. Rosenzweig, C. et al. Assessing agricultural risks of climate change in the $21 \mathrm{st}$ century in a global gridded crop model intercomparison. Proc. Natl Acad. Sci. USA 111, 3268-3273 (2014).

9. Van Herwaarden, A. F., Richards, R. A., Farquhar, G. D. \& Angus, J. F. 'Haying-off, the negative grain yield response of dryland wheat to nitrogen fertiliser-III. The influence of water deficit and heat shock. Aust. J. Agric. Res. 49, 1095-1110 (1998).

10. Ewert, F. et al. Effects of elevated $\mathrm{CO}_{2}$ and drought on wheat: Testing crop simulation models for different experimental and climatic conditions. Agric. Ecosyst. Environ. 93, 249-266 (2002).

11. Ottman, M. J., Kimball, B. A., White, J. W. \& Wall, G. W. Wheat growth response to increased temperature from varied planting dates and supplemental infrared heating. Agron. J. 104, 7-16 (2012).

12. Wall, G. W., Kimball, B. A., White, J. W. \& Ottman, M. J. Gas exchange and water relations of spring wheat under full-season infrared warming. Glob. Change Biol. 17, 2113-2133 (2011).

13. Porter, J. R. \& Gawith, M. Temperatures and the growth and development of wheat: A review. Eur. J. Agron. 10, 23-36 (1999).

14. Amani, I., Fischer, R. A. \& Reynolds, M. P. Canopy temperature depression associated with yield of irrigated spring wheat cultivars in a hot climate. J. Agron. Crop Sci. 176, 119-129 (1996).

15. Bassu, S. et al. How do various maize crop models vary in their responses to climate change factors? Glob. Change Biol. 20, 2301-2320 (2014).

16. Bondeau, A. et al. Modelling the role of agriculture for the 20th century global terrestrial carbon balance. Glob. Change Biol. 13, 679-706 (2007).

17. Fischer, R. Growth and water limitation to dryland wheat yield in Australia-Physiological framework. J. Aust. Inst. Agric. Sci. 45, 83-94 (1979).

18. Iizumi, T. et al. Prediction of seasonal climate-induced variations in global food production. Nature Clim. Change 3, 904-908 (2013).

19. Hertel, T. W., Burke, M. B. \& Lobell, D. B. The poverty implications of climate-induced crop yield changes by 2030. Glob. Environ. Change 20, 577-585 (2010).

20. Reynolds, M. \& Braun, H. in Proc. 3rd Int. Workshop of Wheat Yield Consortium (eds Reynolds, M. \& Braun, H.) ix-xi (CIMMYT, CENEB, 2013).

21. Van Ittersum, M. K., Howden, S. M. \& Asseng, S. Sensitivity of productivity and deep drainage of wheat cropping systems in a Mediterranean environment to changes in $\mathrm{CO}_{2}$, temperature and precipitation. Agric. Ecosyst. Environ. 97, 255-273 (2003).

22. Pradhan, G. P., Prasad, P. V. V., Fritz, A. K., Kirkham, M. B. \& Gill, B. S. Effects of drought and high temperature stress on synthetic hexaploid wheat. Funct. Plant Biol. 39, 190-198 (2012).

23. Mitchell, R. A. C., Mitchell, V. J., Driscoll, S. P., Franklin, J. \& Lawlor, D. W. Effects of increased $\mathrm{CO}_{2}$ concentration and temperature on growth and yield of winter wheat at two levels of nitrogen application. Plant Cell Environ. 16, 521-529 (1993). 
24. Collins, M. et al. in Climate Change 2013: The Physical Science Basis (eds Stocker, T. F. et al.) 1029-1136 (IPCC, Cambridge Univ. Press, 2013).

25. Nelson, G. C. et al. Climate change effects on agriculture: Economic responses to biophysical shocks. Proc. Natl Acad. Sci. USA 111, 3274-3279 (2014).

26. Nelson, G. C. et al. Climate Change: Impact on Agriculture and Costs of Adaptation IFPRI Food Policy Report No. 21 (2009).

27. Cossani, C. M. \& Reynolds, M. P. Physiological traits for improving heat tolerance in wheat. Plant Physiol. 160, 1710-1718 (2012).

28. Rosenzweig, C. et al. The Agricultural Model Intercomparison and Improvement Project (AgMIP): Protocols and pilot studies. Agric. Forest Meteorol. 170, 166-182 (2013).

29. Reynolds, M. P., Balota, M., Delgado, M. I. B., Amani, I. \& Fischer, R. A. Physiological and morphological traits associated with spring wheat yield under hot, irrigated conditions. Aust. J. Plant Physiol. 21, 717-730 (1994).

\section{Acknowledgements}

We thank the Agricultural Model Intercomparison and Improvement Project and its leaders C. Rosenzweig from NASA Goddard Institute for Space Studies and Columbia University (USA), J. Jones from University of Florida (USA), J. Hatfield from United States Department of Agriculture (USA) and J. Antle from Oregon State University (USA) for support. We also thank M. Lopez from CIMMYT (Turkey), M. Usman Bashir from University of Agriculture, Faisalabad (Pakistan), S. Soufizadeh from Shahid Beheshti University (Iran), and J. Lorgeou and J-C. Deswarte from ARVALIS-Institut du Végétal (France) for assistance with selecting key locations and quantifying regional crop cultivars, anthesis and maturity dates and R. Raymundo for assistance with GIS. S.A. and D.C. received financial support from the International Food Policy Research Institute (IFPRI). C.S. was funded through USDA National Institute for Food and Agriculture award 32011-68002-30191. C.M. received financial support from the KULUNDA project (01LL0905L) and the FACCE MACSUR project (031A103B) funded through the German Federal Ministry of Education and Research (BMBF). F.E. received support from the FACCE MACSUR project (031A103B) funded through the German Federal Ministry of Education and Research (2812ERA115) and E.E.R. was funded through the German Science Foundation (project EW 119/5-1). M.J. and J.E.O. were funded through the
FACCE MACSUR project by the Danish Strategic Research Council. K.C.K. and C.N. were funded by the FACCE MACSUR project through the German Federal Ministry of Food and Agriculture (BMEL). F.T., T.P. and R.P.R. received financial support from FACCE MACSUR project funded through the Finnish Ministry of Agriculture and Forestry (MMM); F.T. was also funded through National Natural Science Foundation of China (No. 41071030). C.B. was funded through the Helmholtz project 'REKLIM-Regional Climate Change: Causes and Effects' Topic 9: 'Climate Change and Air Quality'. M.P.R. and P.D.A. received funding from the CGIAR Research Program on Climate Change, Agriculture, and Food Security (CCAFS). G.O'L. was funded through the Australian Grains Research and Development Corporation and the Department of Environment and Primary Industries Victoria, Australia. R.C.I. was funded by Texas AgriLife Research, Texas A\&M University. E.W. and Z.Z. were funded by CSIRO and the Chinese Academy of Sciences (CAS) through the research project 'Advancing crop yield while reducing the use of water and nitrogen' and by the CSIRO-MoE PhD Research Program.

\section{Author contributions}

S.A., F.E., P.M., R.P.R. and D.B.L. motivated the study, S.A. and F.E. coordinated the study, S.A., F.E., P.M., D.C., D.W. and P.D.A. analysed data, D.C., J.W.W., P.K.A., J.A., B.B., C.B., A.J.C., G.D.S., J.D., E.F., M.G-V., S.G., G.H., L.A.H., R.C.I., M.J., C.D.J., K.C.K., A-K.K., C.M., S.N.K., C.N., G.O’L., J.E.O., T.P., E.P., E.E.R., M.A.S., I.Shcherbak, C.S., P.S., T.S., I.Supit, F.T., P.J.T., K.W., E.W., J.W., Z.Z. and Y.Z. carried out crop model simulations and discussed the results, B.A.K., M.J.O., G.W.W., J.W.W., M.P.R., P.D.A., P.V.V.P. and A.C.R. provided experimental data, S.A., F.E., P.M., R.P.R., D.B.L., B.A.K., A.J.C., J.W.W., M.P.R. C.M., A.C.R., M.A.S. and D.W. wrote the paper.

\section{Additional information}

Supplementary information is available in the online version of the paper. Reprints and permissions information is available online at www.nature.com/reprints. Correspondence and requests for materials should be addressed to S.A.

\section{Competing financial interests}

The authors declare no competing financial interests.

S. Asseng ${ }^{1 \star}$, F. Ewert ${ }^{2}$, P. Martre ${ }^{3,4}$, R. P. Rötter ${ }^{5}$, D. B. Lobell ${ }^{6,7}$, D. Cammarano ${ }^{1 \dagger}$, B. A. Kimball ${ }^{8}$, M. J. Ottman ${ }^{9}$, G. W. Wall ${ }^{8}$, J. W. White ${ }^{8}$, M. P. Reynolds ${ }^{10}$, P. D. Alderman ${ }^{10}$, P. V. V. Prasad ${ }^{11}$, P. K. Aggarwal ${ }^{12}$, J. Anothai ${ }^{13 \dagger}$, B. Basso ${ }^{14,15}$, C. Biernath ${ }^{16}$, A. J. Challinor ${ }^{17,18}$, G. De Sanctis ${ }^{19 \dagger}$, J. Doltra2 ${ }^{20}$, E. Fereres ${ }^{21}$, M. Garcia-Vila ${ }^{21}$, S. Gayler ${ }^{22}$, G. Hoogenboom ${ }^{13}$, L. A. Hunt ${ }^{23}$, R. C. Izaurralde ${ }^{24,25}$, M. Jabloun ${ }^{26}$, C. D. Jones ${ }^{24}$, K. C. Kersebaum ${ }^{27}$, A-K. Koehler ${ }^{17}$, C. Müller ${ }^{28}$, S. Naresh Kumar ${ }^{29}$, C. Nendel ${ }^{27}$, G. O'Leary ${ }^{30}$, J. E. Olesen ${ }^{26}$, T. Palosuo ${ }^{5}$, E. Priesack ${ }^{16}$, E. Eyshi Rezaei ${ }^{2}$, A. C. Ruane ${ }^{31}$, M. A. Semenov ${ }^{32}$, I. Shcherbak ${ }^{14,15}$, C. Stöckle ${ }^{33}$, P. Stratonovitch ${ }^{32}$, T. Streck ${ }^{34}$, I. Supit ${ }^{35}$, F. Tao ${ }^{5,36}$, P. J. Thorburn ${ }^{37}$, K. Waha ${ }^{28}$, E. Wang ${ }^{38}$, D. Wallach ${ }^{39}$, J. Wolf ${ }^{35}$, Z. Zhao ${ }^{38,40}$ and Y. Zhu ${ }^{41}$

${ }^{1}$ Agricultural \& Biological Engineering Department, University of Florida, Gainesville, Florida 32611, USA. ${ }^{2}$ Institute of Crop Science and Resource Conservation INRES, University of Bonn, Bonn 53115, Germany. ${ }^{3}$ INRA, UMR 1095 Génétique, Diversité and Ecophysiologie des Céréales (GDEC), F-63 100 Clermont-Ferrand, France. ${ }^{4}$ Blaise Pascal University, UMR1095 GDEC, F-63 170 Aubière, France. ${ }^{5}$ Plant Production Research, MTT Agrifood Research Finland, FI-50100 Mikkeli, Finland. ${ }^{6}$ Department of Environmental Earth System Science, Stanford University, Stanford, California 94305, USA. ${ }^{7}$ Center on Food Security and the Environment, Stanford University, Stanford, California 94305, USA. ${ }^{8}$ USDA, Agricultural Research Service, US Arid-Land Agricultural Research Center, Maricopa, Arizona 85138, USA. ${ }^{9}$ The School of Plant Sciences, University of Arizona, Tucson, Arizona 85721, USA. ${ }^{10}$ CIMMYT Int. Adpo, D.F. Mexico 06600, Mexico. ${ }^{11}$ Department of Agronomy, Kansas State University, Manhattan, Kansas 66506, USA. ${ }^{12}$ CGIAR Research Program on Climate Change, Agriculture and Food Security, International Water Management Institute, New Delhi-110012, India. ${ }^{13}$ Biological Systems Engineering, Washington State University, Prosser, Washington 99350-8694, USA. ${ }^{14}$ Department of Geological Sciences, Michigan State University East Lansing, Michigan 48823, USA. ${ }^{15}$ W.K. Kellogg Biological Station, Michigan State University East Lansing, Michigan 48823, USA. ${ }^{16}$ Institute of Soil Ecology, Helmholtz Zentrum München-German Research Center for Environmental Health, Neuherberg, D-85764, Germany. ${ }^{17}$ Institute for Climate and Atmospheric Science, School of Earth and Environment, University of Leeds, Leeds LS2 9JT, UK. ${ }^{18}$ CGIAR-ESSP Program on Climate Change, Agriculture and Food Security, International Centre for Tropical Agriculture (CIAT), A.A. 6713, Cali, Colombia. ${ }^{19}$ INRA, US1116 AgroClim, F-84 914 Avignon, France. ${ }^{20}$ Cantabrian Agricultural Research and Training Centre (CIFA), 39600 Muriedas, Spain. ${ }^{21}$ IAS-CSIC and University of Cordoba, Apartado 3048, 14080 Cordoba, Spain. ${ }^{22}$ WESS-Water \& Earth System Science Competence Cluster, c/o University of Tübingen, 72074 Tübingen, Germany. ${ }^{23}$ Department of Plant Agriculture, University of Guelph, Guelph, Ontario N1G 2W1, Canada. ${ }^{24}$ Department of Geographical Sciences, University of Maryland, College Park, Maryland 20742, USA. ${ }^{25}$ Texas A\&M AgriLife Research and Extension Center, Texas A\&M University, Temple, Texas 76502, USA. ${ }^{26}$ Department of Agroecology, Aarhus University, 8830 Tjele, Denmark. ${ }^{27}$ Institute of Landscape Systems Analysis, Leibniz Centre for Agricultural Landscape Research, 15374 Müncheberg, Germany. ${ }^{28}$ Potsdam Institute for Climate Impact Research, 14473 Potsdam, Germany. ${ }^{29}$ Centre for Environment Science and Climate Resilient Agriculture, Indian Agricultural Research Institute, IARI PUSA, New Delhi 110 012, India. ${ }^{30}$ Landscape \& Water Sciences, Department of Environment and Primary Industries, Horsham, Victoria 3400, Australia. ${ }^{31}$ NASA Goddard Institute for Space Studies, New York, New York 10025, USA. ${ }^{32}$ Computational and Systems Biology Department, Rothamsted Research, Harpenden, Herts AL5 2JQ, UK. ${ }^{33}$ Biological Systems Engineering, Washington State University, Pullman, Washington 99164-6120, USA. ${ }^{34}$ Institute of Soil Science and Land Evaluation, University of Hohenheim, 70599 Stuttgart, Germany. ${ }^{35}$ Plant Production Systems \& Earth System Science, Wageningen University, 6700AA Wageningen, The Netherlands. ${ }^{36}$ Institute of Geographical Sciences and Natural Resources Research, Chinese Academy of Science, Beijing 100101, China. ${ }^{37}$ CSIRO Agriculture Flagship, Dutton Park, Queensland 4102, Australia. ${ }^{38}$ CSIRO Agriculture Flagship, Black Mountain, ACT 2601, Australia. ${ }^{39}$ INRA, UMR 1248 Agrosystèmes et développement territorial (AGIR), 31326 Castanet-Tolosan Cedex, France. ${ }^{40}$ Department of Agronomy and Biotechnology, China Agricultural University, Yuanmingyuan West Road 2, Beijing 100193, China. ${ }^{41}$ College of Agriculture, Nanjing Agricultural University, Nanjing, Jiangsu 210095, China. 'Present addresses: James Hutton Institute, Invergowrie, Dundee, DD2 5DA, Scotland, UK. (D.C.); Department of Plant Science, Faculty of Natural Resources, Prince of Songkla University, Songkhla 90112, Thailand. (J.A.); European Commission Joint Research Center, via Enrico Fermi, 2749 Ispra, 21027, Italy. (G.D.S.) *e-mail: sasseng@ufl.edu 